\title{
Jornalismos possíveis
}

\section{Possible journalisms}

\section{Clarissa Henning ${ }^{1}$}




\section{Resumo}

Este artigo procura explorar duas novas formas de fazer jornalismo: a Ponte e a agência Pública, entendendo-os como exemplos de resistência à mídia, seja porque questionam as práticas do jornalismo hegemônico, seja porque problematizam o ensino das escolas de jornalismo. Para isso, este trabalho analisa o site de cada uma dessas iniciativas, descrevendo algumas premissas indicadas ali e que servem de guia para compreender o que a Ponte e a Pública entendem ser o jornalismo. Também busca investigar tanto as críticas dirigidas às práticas hegemônicas quanto aquilo que, de acordo com cada site, deve ser preservado do jornalismo tradicional.

\section{Palavras-chave}

Jornalismo, cibercultura, rotinas produtivas, deslocamento das práticas.

\section{Abstract}

This article seeks to explore two new ways to make journalism: Ponte and Pública, which are known as examples of media resistance, either because they question the hegemonic journalism practices or problematize the teaching methods in Journalism schools. Therefore, this article analyses the website of each one of these initiatives, describing some of the premises indicated by them which can help the understanding of the journalism concept developed by them. Besides, the article intends to investigate not only the critics towards the hegemonic practices but also the traditional journalism practices that, according to each one of the sites, should be preserved.

\section{Keywords}

Journalism, cyberculture, productive routines, practice displacement. 
Não temos lados. Não somos ativistas, somos jornalistas. $O$ caminho que escolhemos é o da reportagem, porque é o que sabemos fazer. Tudo o que queremos é ir à rua e contar o que vimos lá. Coisas que fazem a gente se indignar, chorar, rir, berrar. Escolhemos a Ponte porque a gente não gosta de olhar para territórios e fronteiras. Preferimos as possibilidades.

(Fausto Salvadori)

Para nós, o jornalismo não está em crise - está em renovação. $A$ Pública acredita na reportagem. E no repórter. (site da agência Pública, seção "Quem Somos")

A elaboração deste trabalho serve como espaço de experimentação para traços ainda virtuais, parte integrante da aventura de explorar novos olhares sobre os jornalismos, suas práticas e seus profissionais. Parecem ser jornalismos, no plural, porque qualquer prática está necessariamente vinculada aos elementos que Ihe são complementares: são processos de seleção, produção, veiculação e financiamento que guardam diferenças de grau - e talvez, dependendo do ponto analisado, até mesmo de natureza. Tais práticas, discursivas ou não, constituem o mundo em que vivemos, os prazeres e misérias que aí estão, e as condições de possibilidade que os sustentam ou os transformam. A eles e também a nós mesmos.

\section{Ensaiando uma perspectiva de análise}

O jornalismo é uma prática marcada pelas rotinas produtivas e por todo um arcabouço de valores que remete aos ideais de autonomia, independência, verdade, interesse público, objetividade e imparcialidade (TRAQUINA, 2012). Tais premissas emergem no século XIX, tempo em que a industrialização das notícias toma força e dissemina a proliferação de jornais, redações e postos de trabalho correlatos.

A expansão da mídia impressa acontece em um tempo marcado pela lógica da modernidade (COSTA, 2009). Império dominado pela razão e busca da verdade, pela separação clara entre sujeito e objeto. É coerente, portanto, que o jornalismo e suas práticas sejam marcados por tal lógica. Contudo, o formato digital alterou drasticamente a maneira de consumir produtos culturais. 
Mais do que isso: a popularização da internet e das redes sociais trouxe em seu esteio uma crise de suportes sem precedentes (DE MARCHI, 2005). A liberação do polo emissor, antes seara quase exclusiva dos mass media, incentiva a troca e a colaboração entre os internautas (LEMOS, 2007). Assim, a produção de conteúdo alternativo e uma nova forma de distribuição das notícias deslocam a legitimidade do discurso jornalístico.

É claro que é importante perceber a capacidade de flexibilização do capitalismo. Todavia, para além da competência do biopoder² (FOUCAULT, 2008b; HARDT; NEGRI, 2006) em converter o dissenso on-line em proveito próprio, o diferencial desse tempo está no que hoje atravessa tanto o capitalismo de fluxos quanto a resistência a ele: o protagonismo do conhecimento e da colaboração (PRIMO, 2013). Assim, ao invés de destacar somente os problemas dos novos modos de produção e veiculação das informações, importa pensar sobre as condições de possibilidade dessa multiplicidade.

A indústria cultural favoreceu um tipo de jornalismo atravessado por valores marcados pelo capitalismo e pelo mercado, mas a emergência da cibercultura desferiu um golpe contundente na lógica emissor-receptor. Além disso, a vida digital desestabilizou a economia do mercado jornalístico, multiplicando as formas de seleção, produção e veiculação das notícias (ANDERSON; BELL; SHIRKY, 2013). Outras iniciativas jornalísticas - diferentes daquelas ligadas às grandes empresas de comunicação - têm aparecido e a proposta deste artigo é, mediante uma breve pesquisa exploratória, ressaltar certas características de algumas dessas iniciativas.

\section{Pano de fundo da análise: resistência e experimentação}

No final do século XVIII, Kant (2008) publica um texto em que defende que o uso da razão é um processo que pode nos libertar do estado de menoridade. 
Este seria caracterizado por uma obediência a regras alheias, quando nos comportamos e conduzimos nossa vontade de acordo com a autoridade de outro. Assim, o ser humano é responsável pelo próprio estado de menoridade e o uso da razão, de certo modo, dota o indivíduo com a coragem de saber. Mas esse uso toma direções diferentes de acordo com o espaço em que é utilizado: deve ser livre no público e submisso no privado.

O uso privado da razão é aquele em que o homem se comporta como peça em uma máquina, ou seja, "tem um papel a desempenhar na sociedade e funções a exercer" (FOUCAULT, 2008a, p. 339). Já o uso público da razão é o exercido pelo indivíduo como cidadão. Delineia-se assim, de acordo com Foucault, um curioso paradoxo: o uso público e livre da razão é a melhor garantia de obediência. Ao revisitar esse texto de Kant, o autor destaca que sua novidade é marcar a diferença do hoje relacionada à história, ou seja, o que estamos deixando de ser; além disso, o entendimento do Iluminismo como uma tarefa particular destaca o exercício de pensar contra si mesmo: como o "ser" deste tempo poderia ser de outra maneira?

Para além de posicionar-se a favor ou contra o Iluminismo, é evidente que somos marcados por ele. De acordo com Foucault, mais vale perceber a busca pela maioridade como uma atitude filosófica que demarca um ethos de crítica ao ser histórico, no qual o que está em jogo é o esforço de pensar nas fronteiras - uma atitude-limite. Portanto, o exercício do pensamento caminha para a busca dos limites atuais do necessário, ou seja, "do que não é, ou não é mais, indispensável para a constituição de nós mesmos como sujeitos autônomos" (FOUCAULT, 2008a, p. 345).

Seguir as pistas da contingência que nos faz ser o que somos abre a possibilidade de deslocar as práticas que nos constituem. A liberdade, nessa lógica, exige a experimentação de si. É correndo riscos que o indivíduo percebe onde os deslocamentos são possíveis, quais mudanças são desejáveis e como elas podem tomar forma. Recusa, portanto, de qualquer modelo que se intitule universal ou radical. 
A contemporaneidade é marcada pela falência do estado de bem-estar e pela adoção da crise como um modo de vida (ZIZEK, 2011). E é preciso destacar, uma vez mais, que os processos de subjetivação decorrentes do modo de vida contemporâneo integram o uso da razão, tanto público quanto privado. De acordo com Zizek, hoje o que é revolucionário é o capitalismo, que transformou a paisagem do mundo por meio do avanço da tecnologia e da falência da ideologia. A percepção da maioridade foi alinhada em processos de subjetivação próprios da lógica neoliberal. Ser capaz de governar a de si mesmo implica a aceitação da inevitabilidade da realidade socioeconômica do capitalismo, sistema continuamente reiterado pela grande mídia. Fazem parte das restrições a tal sistema a participação nas lutas coletivas e a exigência de que o Estado garanta o acesso aos direitos sociais. Afinal, esta é a era da pós-política, que naturaliza a economia e invalida as possibilidades de antagonismo ideológico.

Na busca pelo estado de maioridade (aquele que prima pelo pensamento contra si mesmo), Zizek também destaca a potência das práticas experimentais: são elas que podem mudar as coordenadas do jogo. Por integrar a constituição mesma de tal processo, a convivência simultânea de acertos e erros torna inevitável a proliferação de monstros. Mas é justamente por meio dessas tentativas que o novo pode emergir.

$\mathrm{Na}$ era das redes, o digital atinge na raiz a ideia de dependência entre armazenamento e distribuição. Uma outra maneira de publicar e fazer circular informações é inaugurada pelas redes eletrônicas, problematizando o papel do jornalista nessa nova configuração de mundo. A velha mídia e as novas possibilidades de emissão convivem nesse tempo que desloca velhos valores e produz outras formas de vida, para além do projeto moderno de identidade e imobilidade. São muitas as informações que possibilitam outra visada de mundo, alternativas àquelas difundidas pelos veículos e empresas da indústria cultural. 


\section{Material empírico}

Este exercício procura explorar duas novas formas de fazer jornalismo: a Ponte e a agência Pública, entendendo-os como exemplos de "resistência à mídia", seja questionando as práticas do jornalismo hegemônico, seja problematizando o ensino das escolas de jornalismo. Para isso, analisa o site de cada uma dessas iniciativas ${ }^{3}$, descrevendo algumas premissas indicadas ali e que servem de guia para compreender o que a Ponte e a Pública entendem ser o jornalismo. Também busca analisar tanto as críticas dirigidas às práticas hegemônicas quanto aquilo que, de acordo com cada site, deve ser preservado do jornalismo tradicional. A construção deste ensaio conta ainda com os discursos proferidos em dois materiais audiovisuais: um pequeno vídeo promocional da Ponte e uma entrevista de Natalia Viana (uma das fundadoras da Pública) concedida ao jornalista Alberto Dines no programa Observatório da Imprensa ${ }^{4}$ em outubro de 2012.

\section{Os sites}

A Ponte é uma iniciativa de quinze jornalistas da imprensa tradicional, que buscavam um lugar para construir e divulgar notícias que não conseguem espaço na mídia hegemônica. Voltada para a produção de pautas sobre segurança pública e violência, a iniciativa conta com trabalho voluntário e não remunerado dos jornalistas envolvidos.

Apesar de registrar o primeiro teste on-line ainda em agosto de 2013, a Ponte passa a veicular o seu conteúdo somente em maio de 2014 . No site, estão dispostas as paletas "Home", "Reportagens", "Notícias", "Análises", "Vídeos", "Indicamos", "Manifesto" e "Quem somos". Dentre elas, gostaria de comentar alguns aspectos das três últimas. 
A paleta "Indicamos" agrupa conteúdos produzidos em outros canais, como documentários, pesquisas e reportagens. É oportuno destacar a indicação de uma matéria veiculada no telejornal Bom dia Brasil, da TV Globo. Esta contrapõe as imagens gravadas em um celular, que mostram um rapaz sendo morto por um policial, e o Boletim de ocorrência, no qual os policiais alegam que a vítima estava armada e que tentou reagir ${ }^{5}$. Tal apontamento indica a importância de analisar a existência de redes de cooperação entre a mídia tradicional e a mídia alternativa, firmadas através de seus profissionais. No caso da Ponte, é importante frisar que seus componentes são profissionais ativos da chamada grande imprensa e que, justamente por isso, mantêm maior proximidade com os jornalistas da iniciativa privada.

Em "Manifesto", o grupo expõe seu entendimento sobre a insustentabilidade da relação estabelecida pela polícia com os cidadãos mais pobres, e anuncia assim o compromisso maior da Ponte: problematizar a segurança pública brasileira. Propõe-se a servir de contraponto à cobertura feita pela mídia hegemônica, indicando os limites que a iniciativa privada impõe tanto ao jornalismo quanto aos jornalistas.

Queremos romper com a visão - presente tanto no jornalismo como nas políticas de segurança pública - que privilegia o centro sobre a periferia e o asfalto sobre o morro. [...] Não temos chefes. Em uma disputa, ouviremos todos os lados porque não aceitamos nenhuma ligação ou subordinação em relação a partidos, governos, corporações ou confissões religiosas.

"Quem somos" subdivide-se em "Autores", "Apoiadores" e "Como participar". O primeiro apresenta os jornalistas do grupo, seguidos de seus colaboradores. "Apoiadores" apresenta uma longa lista de instituições e pessoas que emprestam seus nomes à iniciativa, agregando credibilidade ao 
veículo. Entre as instituições, aparece uma diversidade de organizações, como Associação Juízes para a Democracia, Associação dos Profissionais e Amigos do Funk, Comissão Pastoral da Terra, Mídia NINJA, MST e Mães de Maio. Entre as pessoas que apoiam a Ponte, figuram intelectuais, ativistas, advogados, jornalistas, rappers e sociólogos, entre outros profissionais. Além da diversidade profissional de tais apoiadores, é interessante destacar outros dois nomes que constam na lista e que são caracterizados não pela formação ou atuação, mas pela experiência pessoal com as contradições da segurança pública brasileira:

Daniel Eustáquio de Oliveira - funcionário público e pai que investigou e comprovou o envolvimento de policiais militares de SP na morte de seu filho, César Dias de Oliveira, em julho de 2012 [...] Vânia Lúcia da Silva Alves - dona de casa que ajudou a esclarecer o assassinato do irmão, Antonio Carlos Silva Alves, o Carlinhos, morto em 2008 por policiais militares pertencentes ao grupo de extermínio conhecido por Highlanders.

A paleta "Como Participar" abre espaço para sugestões de pauta e envio de reportagens, fotos e artigos pelos usuários. Por outro lado, deixa claro que o trabalho é voluntário e sem remuneração. O site ainda destaca o apoio da agência Pública, apontando para a importância da formação de redes entre os novos modelos de jornalismo:

A Ponte nasce com o apoio institucional da Agência Pública de jornalismo investigativo, uma organização sem fins lucrativos pioneira no Brasil, que visa ao fortalecimento do direito à informação, à qualificação do debate democrático e à promoção dos direitos humanos. É sob esse prisma que deve ser vista a sua participação na fundação da Ponte, fornecendo apoio institucional e estrutura, como incubadora do projeto (grifos do original).

A Pública é inaugurada em março de 2011. É uma agência de jornalismo investigativo que produz reportagens aprofundadas sobre temas prioritariamente articulados aos direitos humanos. Conta com o trabalho de nove jornalistas, financiado tanto por crowdfunding (doações do público) quanto por editais de fundações. 
O site da Pública é dividido entre seis paletas principais: "Reportagens", "Especiais", "Copa pública", "Da redação", "Vídeos" e "Quem somos". Neste ensaio, destaco a seção "Jornalismo" (dentro de "Reportagens"), a paleta "Quem somos" e suas seções "Parcerias" e "Republique".

Em "Quem somos", explicita-se a vinculação da iniciativa a um dos modelos emergentes da nova economia da cultura: o copyleft. O texto explica que todo o conteúdo da agência é registrado em Creative Commons (CC), uma forma de licença que flexibiliza a propriedade intelectual dos produtos culturais ${ }^{6}$. Dessa forma, outros veículos de comunicação reproduzem o conteúdo da agência, que tem por meta a produção de reportagens fundamentadas no interesse público e produzidas "do ponto de vista da população - visando ao fortalecimento do direito à informação, à qualificação do debate democrático e à promoção dos direitos humanos".

As seções "Parcerias" e "Republique" estão vinculadas às possibilidades das novas tecnologias na economia da cultura. Em "Parcerias", estão elencadas organizações de jornalismo independente brasileiras e estrangeiras, além de veículos da grande imprensa e de iniciativas inovadoras do espaço digital. Em "Republique", a Pública convida tanto pessoas jurídicas como físicas a replicar o conteúdo da agência, explicando as condições de uso vinculadas à licença escolhida no Creative Commons.

Uma das iniciativas da Pública é a premiação de projetos de reportagem, elaborados por jornalistas independentes, através de microbolsas. Sob "Jornalismo" abrigam-se o edital referente à premiação e conteúdos relacionados às produções vencedoras deste projeto, além de outros materiais. Dentre estes: qualquer usuário pode registrar conteúdo intelectual - seja texto, vídeo ou som. O projeto prevê cinco tipos de licença, variando somente o grau de flexibilização dos direitos autorais. No caso da Pública, a agência autoriza o uso de qualquer material, desde que citada a fonte. Além disso, impede o uso de somente excertos das reportagens. De acordo com o site da Pública, essa medida é necessária para evitar o perigo da descontextualização dos fatos. 
um disponibiliza um minidocumentário sobre o funk ostentação; outro convida o leitor para elaborar perguntas aos candidatos à presidência da república; dois discutem o crowdfunding para o jornalismo; um relata a história de um jornalista que pediu demissão por não se adequar às práticas da iniciativa privada; e outras três matérias versam sobre um novo modelo de fazer jornalismo - a Ponte.

Em seu site, a Pública abre espaço para fundamentar o apoio a Ponte. Um dos textos é assinado pelo jornalista da Ponte, Fausto Salvadori. Ele descreve sua experiência como repórter de polícia, a relação quase incestuosa entre esse jornalismo e as práticas da polícia, e a frustração que sente com o mecanismo jornalístico que hierarquiza as vítimas da violência - e que define a visibilidade ou não de suas histórias. Relata o encontro com outros jornalistas que, como ele, sentiam a necessidade de criar algo para além dessa hierarquia e de provar que o jornalismo pode sim ser de outra maneira: "estamos aprendendo a fazer jornalismo sem pensar no que ele é, mas no que a gente acredita que pode ser" (grifos nossos).

Em outro texto, Natalia Viana e Marina Amaral afirmam que a incubação da Ponte pela Pública funciona no sentido de dar visibilidade ao projeto e de alargar o alcance de novas formas de fazer jornalismo. Além disso, as jornalistas explicam que a agência tem como função ajudar na elaboração da pauta da Ponte:

Do ponto de vista editorial, as diretoras da Pública, Marina Amaral e Natalia Viana, participam como jornalistas que compõem o conselho que define pautas, e outros conteúdos de publicação, sempre dentro do maior rigor técnico e ético que constituem um patrimônio comum.

Outra expectativa que une os projetos é a de que, a partir de novos olhares sobre velhas problemáticas, tomem fôlego outras perspectivas na elaboração de políticas públicas - aqui, claro, referindo prioritariamente aquelas voltadas para os impasses da segurança pública. 
Tanto na Pública quanto na Ponte, o uso das ferramentas digitais é comum: Google Plus, Facebook, Twitter, YouTube e Instagram estão vinculados nos dois sites. A "Home" da Pública deixa clara a importância das novas práticas digitais ao disponibilizar tanto uma listagem das reportagens "Mais recentes" quanto uma listagem das "Mais compartilhadas". Já a "Home" da Ponte só disponibiliza "Mais recentes" - isso talvez se deva à sua história, ainda muito curta (apenas seis meses de produção).

Além de ter mais de cinco anos de existência, a Pública remunera seus jornalistas e por isso conta com uma periodicidade maior; por seu turno, a Ponte depende do trabalho voluntário de jornalistas que atuam em outros veículos, o que concorre para que seu conteúdo e periodicidade sejam mais escassos.

\section{Os materiais audiovisuais}

Os dois vídeos reunidos para essa análise são ricos materiais para quem procura seguir as pistas das novas formas de fazer jornalismo. E isso não só pelas críticas que fazem à prática jornalística da iniciativa privada, mas também porque indicam vários atravessamentos entre elementos diferentes, mas complementares. Assim, não é possível falar de financiamento alternativo sem aludir, ao mesmo tempo, às novas relações possibilitadas pela sociedade em rede. Por outro lado, aponta-se que o uso das ferramentas digitais não pode prescindir da presença do repórter ali onde as relações humanas tornam-se palpáveis, ou seja, na rua.

Nos dois materiais, há ressonância quanto ao fato da mídia tradicional não cobrir temas relacionados aos direitos humanos. O vídeo da Ponte destaca especificamente a omissão quanto à cobertura da violência policial e da rotina de desrespeitos que a população negra brasileira está submetida.

Ao falar sobre o financiamento do Terceiro Setor, Natalia Viana destaca que os editais das fundações que mantêm a Pública não deixam de ter suas agendas ${ }^{9}$. 
Por outro lado, uma delas é justamente a democratização da comunicação e o acesso à informação como um dos direitos fundamentais do homem.

Bruno Paes Manso, da Ponte, sublinha a importância das novas tecnologias e da participação de pessoas comuns na elaboração e veiculação da reportagem:

Eu acho que hoje um celular flagrando um policial batendo em uma pessoa tem mais peso até do que a Corregedoria, que sempre, de alguma forma, acaba passando um pano nessas situações. Então acho que o jornalismo independente, a quantidade de gente vendo essas informações, ela consegue mais efetivamente contrabalancear o poder das autoridades nas ruas, são mais olhos olhando.

Ao referir-se à premissa jornalística de fiscalizar os poderes, Natalia Viana lembra que todos devem ser monitorados: governo, empresas, movimentos e ONGs. Nesse sentido, a jornalista diz que a transparência dos dados públicos facilita o trabalho do jornalista, mas que é preciso uma mudança cultural para que os profissionais atentem para as massas de dados disponíveis. Natalia ressalta que, para além de conhecer os locais onde são disponibilizados e saber como utilizar tais informações, o jornalista deve ser capaz de compreender que muitas vezes há dados que são omitidos e outros que estão errados.

A tecnologia e suas condições de possibilidade são fonte de atravessamentos diversos. Por um lado, elas servem de ponto de integração entre jornalistas e público - tanto para a construção da notícia (caso do celular, apontado por Manso) quanto no compartilhamento das reportagens (caso do Facebook, situação indicada em uma fala de Natalia Viana). Por outro lado, em uma inovadora percepção sobre a internet, é também Natalia Viana quem aponta que o lugar da notícia "velha" é... a web.

\footnotetext{
A gente sempre fala que, na verdade, nós somos bastante caretas. 0 jornalismo que a gente produz é um jornalismo à antiga, é o jornalismo de sujar as solas dos sapatos. [...] A Marina Amaral, que é diretora da Pública comigo, diz que na internet só tem notícia velha, e é verdade. A reportagem é aquela que vai trazer o que ninguém viu, o que ninguém experimentou, o que ninguém descobriu até então. É ela que vai trazer o "algo novo".
} 
As práticas possibilitadas pelas novas tecnologias foram absorvidas pelo mercado de forma a alijar o processo de apuração da notícia. Otimiza o compartilhamento, mas reduz drasticamente o tempo dedicado à verificação dos fatos. O trabalho da Pública viria, assim, para suprir a grande imprensa de um tipo de material que esta precisa, mas que não tem mais condições de produzir. Para ilustrar essa ideia, a jornalista relata uma conversa que teve com um editor de um grande portal que é parceiro da Pública:

Um editor desses sites grandes me falou: "Nossa, Natalia, eu acho muito legal o que vocês fazem porque eu não posso deixar um repórter meu dois dias numa pauta". Caiu meu queixo, porque eu falei: "Nossa, se me derem dois dias para fazer uma pauta eu acho que me mato!". Os nossos repórteres ficam uma semana, no mínimo!

Por outro lado, Natalia frisa que a reportagem é somente um de muitos tipos de jornalismo, e que quanto mais tipos houver, melhor. O que a jornalista lamenta é o fato de que o modelo atual do jornalismo hegemônico impossibilita o exercício da reportagem aprofundada.

No âmbito das discussões sobre a prática da grande reportagem, Alberto Dines questiona Natalia Viana sobre a formação nas escolas de jornalismo, já que é a universidade quem fornece a mão de obra para a produção da notícia. A jornalista defende a necessidade de adequar a visão que as pessoas têm do jornalismo investigativo; não é uma aventura, mas trabalho árduo e muitas vezes maçante. Aqui há uma via de mão dupla: por um lado, os jornalistas recém-formados saem desanimados por desconhecerem as possibilidades de trabalhar com jornalismo sério e de qualidade; por outro lado, muitas vezes as escolas de jornalismo não exigem a prática da grande reportagem e por isso os estudantes não sabem que ela é possível e que existe.

O peso da experiência dos jornalistas na elaboração da reportagem de qualidade é ressaltado tanto por Natalia Viana quanto pelos integrantes da Ponte. A jornalista da Pública informa que aprendeu jornalismo com profissionais calejados e que isso determina a elaboração do trabalho, mas que a equipe da 
agência também conta com um pessoal mais novo que nasceu com a internet e que projeta a reportagem já pensando nas redes sociais. Ao destacar a experiência dos integrantes, a jornalista Maria Carolina, da Ponte, indica que a experiência em veículos da grande imprensa é importante não só pela vivência, mas também como medida de resistência desses profissionais: há outro jornalismo que é possível fazer, para além daquele experimentado na iniciativa privada.

\begin{abstract}
A gente juntou um grupo importante de jornalistas já com bastante experiência, cada um na sua área, e a gente vai fazer o melhor que a gente pode fazer, sempre sonhou em fazer, e não tinha para onde fazer [...] É por isso que a gente está querendo fazer esse canal alternativo de jornalismo, para dar voz para essas outras situações que acontecem no Brasil e que não aparecem no jornal tradicionalmente.
\end{abstract}

Outro ponto de destaque é que, para a Pública, conhecer o público pode funcionar como um fator limitador do jornalismo de qualidade. Isso porque a produção da reportagem pode tomar como medida a satisfação da audiência, o que comprometeria a construção da notícia. Assim, a Pública abre mão de métricas que produzam o perfil de sua audiência em favor da qualidade da notícia e da experimentação no jornalismo.

Não sabemos, e é aí que está: o nosso princípio é experimentar. $\mathrm{Na}$ verdade, esse é o princípio da internet, [...] mesmo o Google, o Facebook. Os empreendimentos na internet têm que ser constantemente renováveis, e não existe fórmula. O que você faz é: você testa e vê o que funciona e o que não funciona. Isso é ótimo.

\title{
Pistas para a abertura de caminhos: no rastro dos jornalismos possíveis
}

Tanto nos textos veiculados nos sites quanto nas falas contidas nos materiais audiovisuais, a referência à experimentação é repetida. Problematizar o jornalismo passa pela sua reinvenção, pela sua ultrapassagem, pela sua diferenciação. $O$ estudo dos materiais que compõem o corpus desse ensaio ajuda a pensar nos modos pelos quais o poder se instala nos corpos, tanto dos jornalistas quanto dos acadêmicos. Ajuda também a compreender como se 
dá a resistência dos profissionais às regras e normas que integram o universo acadêmico e mercadológico da produção da notícia.

Nos dois empreendimentos analisados, a elaboração da reportagem parte do ponto de vista de quem teve seus direitos mais fundamentais prejudicados. Aqui, a multiplicidade de correlações de força que constituem a rede do jornalismo hegemônico é contrabalanceada por uma outra perspectiva. $E$ isso não quer dizer que o jornalismo tradicional não siga existindo nesses outros jornalismos: pelo contrário. Ele é retomado em sua medida de qualidade para a apuração da notícia, de forma a ser associado às ferramentas oportunizadas pelas novas tecnologias.

O que importa é distinguir "jornalismo hegemônico" ou "jornalismo comercial" de "jornalismo tradicional", porque parece que não se referem às mesmas práticas. Lançar mão das novas tecnologias em proveito da mais-valia seja na exploração da rede de contatos pessoal ou na pura e simples exploração do tempo de trabalho do jornalista - é desqualificar a produção da notícia. Reduzir prazos de apuração em proveito da produção e compartilhamento massivo de conteúdo é servir a forças alheias ao interesse público e à cidadania.

Outro apontamento a ser levado em consideração é o exercício da prática da grande reportagem nas escolas de jornalismo. Seu desuso talvez se deva a um desencantamento do próprio corpo docente, na medida em que muitos professores são também jornalistas vinculados ao mercado de trabalho. Por outro lado, o desconhecimento dos estudantes sobre as possibilidades que a nova economia da cultura oferece para a produção de outras formas de jornalismo precisa ser problematizado. Nesse sentido, parece necessário analisar os currículos dos cursos de jornalismo, para verificar se oferecem disciplinas e/ ou projetos de extensão que preparem os futuros profissionais para relações alternativas ao patronato (empregados em grandes redações ou em assessorias de imprensa).

A nova economia da cultura oferece outras possibilidades, sem dúvida, mas é antes de tudo um jogo que guarda diferentes potências. A aplicabilidade de suas práticas pode ir tanto ao encontro de "forma de vida artística", como 
também pode servir para revigorar formas terminais de poder. $E$ essa parece ser mais uma razão para que o estudo do Terceiro Setor tenha uma importância fundamental nas escolas de jornalismo. Até porque as práticas jornalísticas são parte fundamental da composição do arquivo; afinal, a disputa da constituição da memória coletiva também está em jogo.

A resistência ao modo de produção do jornalismo hegemônico aponta para a luta pela produção do arquivo: é o arquivo como arma, de forma a garantir visibilidade ao interesse público. Como mostram os discursos descritos aqui, é preciso estar atento aos usos da inovação e aos seus efeitos - tanto no conhecimento do jornalismo quanto no trabalho dos jornalistas.

\section{Referências}

ANDERSON, C. W.; BELL, E.; SHIRKY, C. Jornalismo pós-industrial: adaptação aos novos tempos. Revista de Jornalismo ESPM, São Paulo, v. 2, n. 5, p. 30-89, abr./jun. 2013.

COSTA, C. T. Ética, jornalismo e nova mídia: uma moral provisória. Rio de Janeiro: Zahar, 2009.

DE MARCHI, L. A angústia do formato: uma história dos formatos fonográficos. E-Compós, Brasília, v. 2, 2005.

FOUCAULT, M. Arqueologia das ciências e história dos sistemas de pensamento. Rio de Janeiro: Forense Universitária, 2008a. (Ditos e escritos, v. 2).

. Nascimento da biopolítica. São Paulo: Martins Fontes, 2008b.

HARDT, M.; NEGRI, A. Império. Rio de Janeiro: Record, 2006. 
KANT, I. A paz perpétua e outros opúsculos. Lisboa: Edições 70, 2008.

LEMOS, A. Cibercultura: tecnologia e vida social na cultura contemporânea. Porto Alegre: Sulina, 2008.

PRIMO, A. Interações mediadas e remediadas: controvérsias entre as utopias da cibercultura e a grande indústria midiática. In: PRIMO, A. (Org.). Interações em rede. Porto Alegre: Sulina, 2013. p. 13-32.

TRAQUINA, N. Teorias do jornalismo: porque as notícias são como são. Florianópolis: Insular, 2012. v. 1.

ZIZEK, S. Primeiro como tragédia, depois como farsa. São Paulo: Boitempo, 2011.

submetido em: 28 abr. 2016 | aprovado em: 28 jun. 2016 